perature gradient decreases (lapse-rate increasing, in the usual meteorological terminology) with height, or wind speed increases, or there is a suitable combination of both effects.

In Meteorological Report No. 18*, Mr. G. A. Corby of the Meteorological Office describes how Dr. Scorer's theory can be exploited by forecasters when advising pilots on the nature of the airflow over mountains. $\mathrm{He}$ gives a number of reports of waves encountered * Air Ministry : Meteorological Office. Meteorological Report
No. 18: Air Flow Over Mountains-Notes for Forecasters and Pilots. By G. A. Corby. Pp. ii + 53. (London: H.M. Stationery Office, 1957.) By G. A.
$3 s$. net. by aireraft, and shows how the occurrence of the waves in question was to be expected from the atmospheric structure. A suitable diagram for computing $l^{2}$ is given with instructions for its use in forecasting.

The report also contains diagrams of the flow of air in lee waves computed from the general theory and an account of such effects as the increase in liability to ice formation, given suitable air temperature and humidity, in the waves because the ascent of the air has the effect of lowering the height of the freezing-level. G. A. BULL

\title{
MOUNT STROMLO OBSERVATORY
}

\section{REPORT FOR 1957}

$\mathrm{T}$ $\mathrm{HE}$ annual report of Mount Stromlo Observatory for $1957^{*}$ deals first with the transfer of the Observatory to the Australian National University on January 3, 1957, when the Commonwealth Observatory of the Department of the Interior officially ceased to exist. All the members of the scientific staff of the Observatory were transferred to the Department of Astronomy of the Research School of Physical Sciences of the Australian National University, the official name of the Observatory then becoming 'Mount Stromlo Observatory'. Arrangements were made not only to safeguard the financial status of the staff but also to protect an area of about $3 \frac{1}{2}$ square miles in which the Observatory buildings are situated "from invasion by industry, commerce or any development relating to the growth of the nearby capital city of Canberra".

Following the departure of Dr. R. v. d. R. Woollev in December 1955, Dr. A. R. Hogg assumed the post of acting director of Mount Stromlo Observatory, a position which he retained until Dr. Woolley's sueeessor, Dr. B. J. Bok, took office in March 1957, and on his arrival became head of the newly formed Department of Astronomy at the Australian National University. Tribute is paid to the valuable work accomplished during Dr. Hogg's tenure of office, and on Dr. Bok's arrival he was appointed assistant director.

Tests of the 74-in. mirror by Dr. Hogg, with the assistance of Mr. K. Gottlieb, proved the existence of astigmatism in excess of the maximum permissible amount, and while steps are being taken to remedy this, the telescope during the interim is used for photoelectric, spectrographic and photographic work. Under Dr. Hogg's direction the mirror was successfully aluminized. The 50-in. Melbourne reflector has been overhauled in the Design Department and the workshop. Motorization of the fast motion in right ascension has been completed and provisions have been made for Selsyn repeater systems in both declination and right ascension. Other alterations have been made and an important work plan is well under way to replace the present $f / 2$ spherical primary with an $f / 4.5$ paraboloid and a conventional Cassegrain mirror for the entire system to operate at $f / 18$. The 30-in. Reynolds reflector, which continues to be in regular use, is overdue for a complete mechanical and electrical overhaul. Short notes appear on the other instruments, including the 20 -in. Catts reffector,

* Australian National University : Mount Stromlo Observatory. Annual Report for the Year 1957. Pp. 22. (Canberra: Australian National University, 1958.) the 8-in. $f / 1$ Schmidt, and the photographic zenith tube, and considerable space has been devoted to Dr. T. Dunham's plans for a coudé spectrograph on the 74-in. reflector. The spectrograph will be enclosed in a housing with double walls $24 \mathrm{ft}$. long and $16 \mathrm{ft}$. wide, and air at constant temperature will circulate between the two layers of the wall, thereby avoiding thermal effects on the instrument.

Among other matters dealt with are observation of artificial Earth satellites. It is emphasized that Mount Stromlo Observatory is not officially involved in the observation of artificial satellites and the names of other institutions and also individuals are referred to in connexion with this work. Nevertheless, Sputnik $I$ was kept under observation, and later Dr. A. Przybylski carried out observations of other satellites and did a considerable amount of work on their orbits. $\mathrm{He}$ also issued duplicated copies of predicted times of observation which proved to be very reliable.

Eight vacation scholars selected from undergraduate students in physics and mathematics at the Universities of Melbourne, Adelaide, Queensland and Sydney were appointed for the summer months, and each scholar has been assigned as a special assistant to a staff member. These scholars hold weekly colloquia, attend weekly informal discussion meetings, and participate in the night observing, acting as night assistants on the 74-in. reflector during staff vacations. They live in University House, conduct the visitors around during the day-time and participate fully in many other Observatory activities. It is hoped that during 1958 the first appointments will be made to regular scholarships leading to the Ph.D. degree.

Public visits to the Observatory both by day and night have been remarkably popular; to accommodate the great demand for visits by night the Director has instituted a series of monthly visitors' nights, with an average attendance of 150 people, and on these nights most telescopes are open for inspection. Estimates of the number of visitors show that there have been about 3,500 day-time visitors, 500 Wednesday visitors and 1,000 visitors during the seven special evenings. A booklet has been issued which gives information about the Observatory and its work. A list of the names of the twenty-two members of the Observatory staff and a catalogue of papers published during 1957 appear at the end of the report. 